\title{
Exposing Engineering Students to Ethical Challenges: A Web-BASED LEARNing MOdULE
}

\author{
Leonnie Kavanagh, PhD, P. Eng., ${ }^{1}$ Kim Laberinto, ${ }^{1}$ and Douglas Ruth, PhD, P. Eng. ${ }^{l}$ \\ ${ }^{1}$ Centre for Engineering Professional Practice and Engineering Education, Faculty of Engineering, University of Manitoba \\ Corresponding Author: leonnie.kavanagh@umanitoba.ca
}

\begin{abstract}
This paper presents the development of an interactive web-based module on the 'Code of Ethics' for the practice of professional engineering in Manitoba.

The module highlights the importance of ethics, casestudies with 'branching' options for a variety of realworld scenarios of ethical or unethical choices, and tests with automatic feedback that track a students' progress.

Once implemented, this module is expected to form the foundation for future e-modules in various engineering courses at the University of Manitoba.
\end{abstract}

Keywords: eLearning: module: engineering code of ethics: web-based learning.

\section{INTRODUCTION}

In 2015, the Faculty of Engineering, University of Manitoba, developed an e-module to deliver a selfdirected and engaging learning experience for students on the 'Code of Ethics' for the practice of professional engineering in Manitoba.

Imagine students learning directly from the consequences of their ethical decisions by being immersed in a dynamic and stimulating environment and faced with ethically challenging scenarios. Using this ethics e-module will allow students to apply their knowledge of the fundamental cannons of the engineering code of ethics and, by doing so, experience the very same thought process that real engineers encounter in the workplace. "Our engineering acts, bylaws and codes of conduct affirm that engineering is about more than just crunching numbers, it is about more serving the needs of society and creating solutions that work" [7]. By allowing student engineers to be "agents in the ethical scenarios rather than observers" [3], they will "develop a deeper understanding of the impact of engineering on society" [7].

Learning is emphasized throughout the ethics e-module with animation, interactive software, and videography to inspire students. Presented with professors' and professional engineers' experiences with ethics, students will realize that ethical conflicts are not rare incidents.
The animated case studies of various engineering successes and engineering failures in the ethics e-module will show young engineers their responsibility in making the 'ethical' decision.

Figure 1 shows a screenshot of the ethics e-module design with a feature that allows students to select the images of their mentor throughout the module.

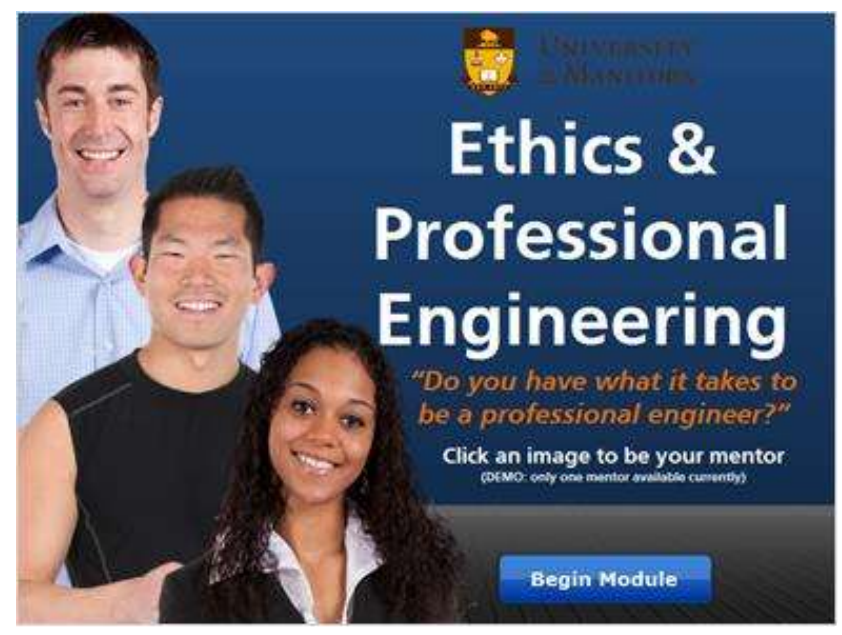

Fig. 1. Ethics e-module design.

The ethics e-module is expected to be implemented in the fall of 2016, and will likely form the foundation for future e-modules such as risk management, project management, and engineering economics, which will help to satisfy the requirements of the Canadian Engineering Accreditation Board (CEAB) at the University of Manitoba.

\subsection{Objective}

The objective of the paper is to present the University of Manitoba's 'Code of Ethics' e-module for the practice of professional engineering in Manitoba.

The module was designed to be:

- Interactive

- Immersive 
- Intuitive

- Informative

- Dynamic

- $\quad$ Accessible to the visually and hearing impaired

- $\quad$ Easily implemented by professors

\section{METHODOLOGY}

The ethics e-module was developed based on setting clear objectives, and deciding on desired content, design process and achievable attributes.

Figure 2 presents the flowchart of the process used to develop the ethics e-module.

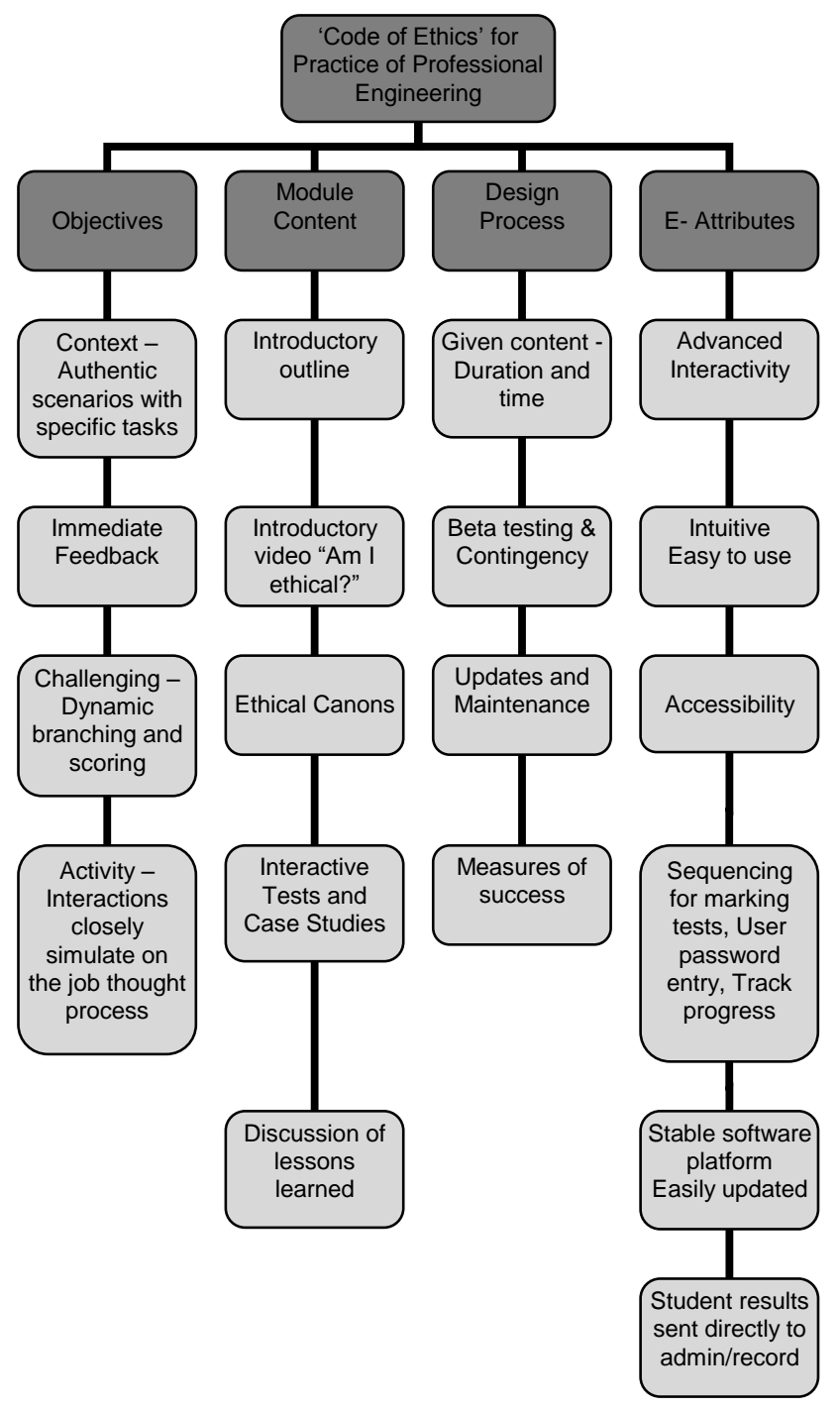

Fig. 2. Flowchart of ethics e-module methodology.

\subsection{Software, Vendors and Platforms}

'Articulate Storyline 2' [1] was selected as the 'authoring' software for the e-module platform. In addition, templates were purchased from 'e-Learning Brothers' [5] and used to provide copyright images and stock photos throughout the module. The e-learning tools, platforms, and vendors were essential to executing the features desired for the emodule. The software platform was evaluated and selected based on the ability to execute the following features:

- Produce branching and dynamic segmentation steps (e.g. test sequencing of responses, instead of just 'true/false/yes/no' responses)

- Track and display student progress

- Provide a stable software platform

- Able to easily update/change content without administrator

- Send students' results directly to administrator or records

- Produce certificate or Authentication of emodule completion

- $\quad$ Provide password entry accessible to a student

\subsection{Branching and Dynamic Segmentation}

Since the student's journey, choices, and critical thinking are important to the ethics learning process, the 'Articulate storyline2' branching technique was used for the interactive case studies and for marking tests in this emodule. 'Articulate Storyline2' provides a built-in tool to help create and place different steps and choices in the interactive case study. The mechanism can dynamically segment the critical steps of how the student arrived at an ethical decision, instead of the typical true/false questions.

Scenarios and case studies using 'Choose-your-ownAdventure' branching [4] allows the student to explore the outcomes of their ethical choices; some choices may end in "failures", while others may end in "successes", both with varying degrees of consequences.

A risk assessment of the branching and dynamic segmentation technique was conducted for the e-module. For example, there was a concern that the technique may not be able to select, examine, and approve all potentially 'acceptable' branching options. Therefore, students may not receive credit for an 'acceptable', but obscure, ethical choice. This risk can be overcome by giving students the option to appeal and have their responses reviewed by professors after completing the e-module.

\section{MODULE CONTENT}

Scenarios and interactive case-studies that accurately reflect the experiences of engineers in the real world were developed and critiqued, along with a wide array of choices for the students to explore. 
A major source for the case study content for the emodule was obtained from the University of Manitoba "Engineering Ethics", Minerva/MITAC's Engineering Modules Project [6]. Many of the case studies were derived from real-world investigations by the Association of Professional Engineers and Geoscientists of Manitoba (APEGM) [2].

The ethics e-module included the following content:

- Introductory video

- Introductory outline

- Ethical cannons

- Interactive case studies

- Mini-tests

- $\quad$ Final test, and

- Discussion of lessons learned

The details of the e-module contents are presented.

\subsection{Introductory Video}

A $2 \frac{1}{2}$-minute introductory video on 'what ethics mean to me' was shot and edited in-house by the University of Manitoba for the e-module. The duration of the video was kept short, since it was anticipated that longer than 3 minutes risked losing the student's attention. The video included local Manitoba engineering students and professional engineers and is intended to inspire and inform students about the ethical practice of engineering, while maintaining a positive atmosphere during the viewing.

The introductory video was designed to be:

- $\quad$ Sleek

- Modern

- Professional

- $\quad$ Relevant to all students (young and mature)

\subsection{Introductory Outline}

An introductory outline was included in the e-module informing the students how to navigate the content. This included an interactive series of slides to introduce the content of the course and how to effectively learn from it.

The introductory outline included the following qualities:

- $\quad$ Engaging

- Interactive

- Informative

\subsection{Ethical Canons}

The five fundamental canons and sub-canons of the APEGM 'Code of Ethics' for Manitoba, are the cornerstone of the e-module.

Students can read the APEGM canons, and know and differentiate between them in the proposed case studies.
The canons are interactive and students have the ability to hover over each cannon of conduct in order to learn more.

Figure 3 shows a screenshot of the fundamental canons of APEGM in the ethics e-module.

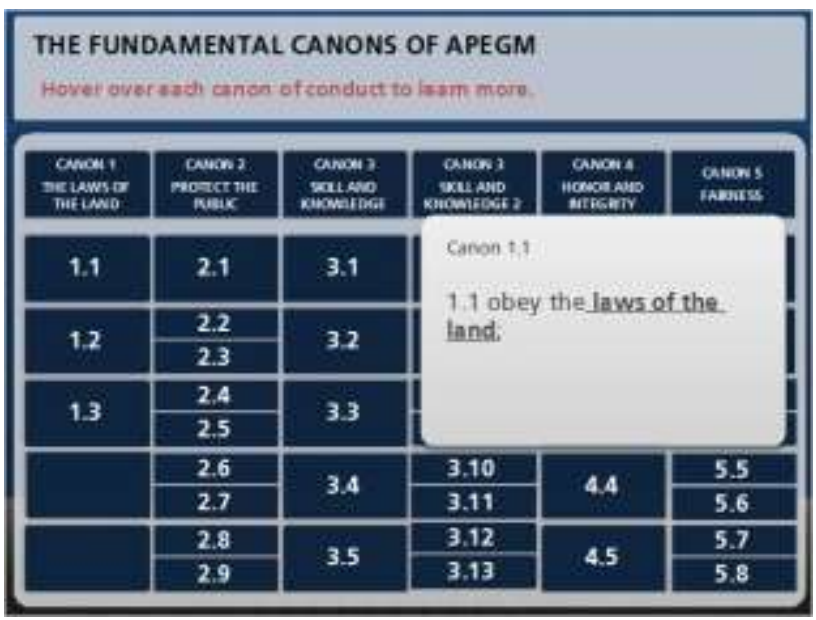

Fig. 3. Fundamental canons of APEGM in ethics emodule.

\subsection{Interactive Case Studies}

Interactive case studies of real-world scenarios is a key component in the e-module and is a large portion of where students will experience making choices; 'ethical' or 'unethical' ones.

The students are presented with scenarios where they must exercise their ethical thinking processes. The case studies are reflective of some examples of the reality that engineers face in the workplace. They are to reinforce the process of ethical thinking in the students' mind, and encourage them to use the same thought process when encountering ethical dilemmas once they graduate.

As there are many various ethical scenarios that engineers encounter in the workplace, the case studies found in the e-module are not meant to be exhaustive. New case studies will be developed and used randomly in the e-module.

Figure 4 shows a screenshot of five interactive case studies developed for the ethics e-module.

For example, in 'The Reporter' case study students explore the scenario where a reporter suddenly asks them for their technical advice on a controversial engineering report in which they were not involved. Will they respond ethically?

Figure 5 shows a screenshot of one 'choose-yourresponse' branching options the students can take in the interactive case study 'The Reporter'. 


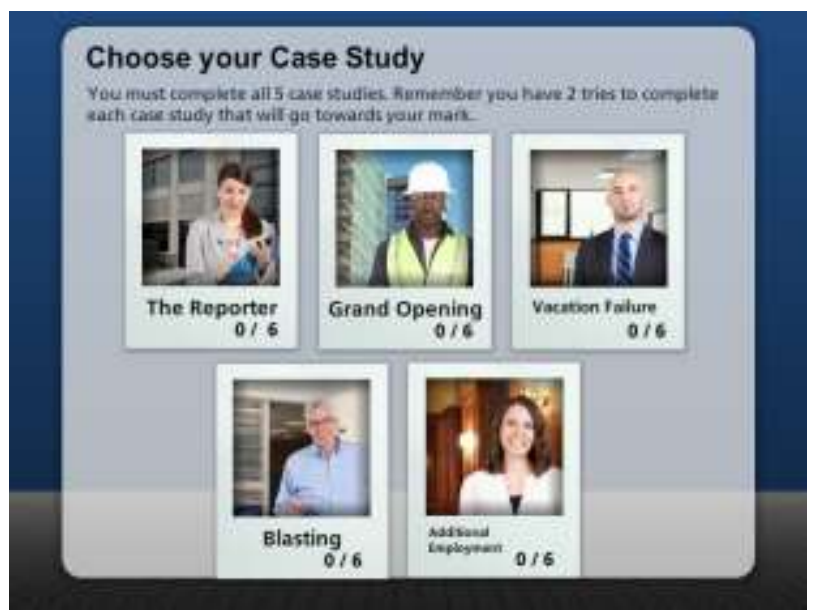

Fig. 4. Interactive case studies in ethics e-module.

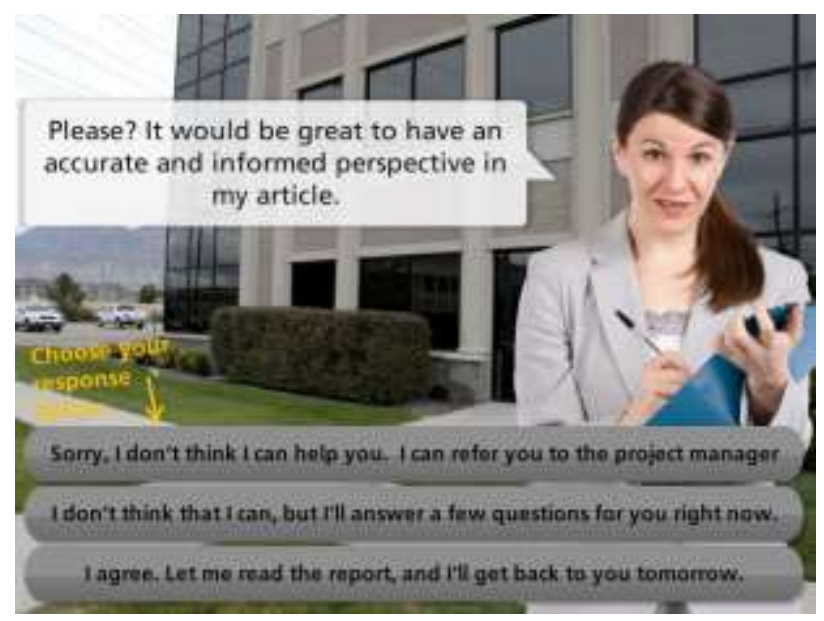

Fig. 5. 'Choose-your-response' branching in interactive case study 'The Reporter'.

\subsection{Mini and Final Tests}

Two mini-tests and a final test provide students with immediate feedback of their progress and knowledge of the ethical cannons and case studies. The tests are used to evaluate the student's ability to grasp the great variety of ethical choices in the scenarios presented.

For example, mini-test\#1 on the 'Ethical Canons', includes (but not limited to) identifying the canons violated in a real world situation. Mini-test\#2 on the 'Case Studies', includes interactive case-studies with branching 'choose your-own-adventure' technique having a number of ethical choices that will be required to be completed by the student. The final test is a multi-part case study of a scenario that assesses the student's overall critical thinking on engineering ethics.

Figure 6 shows a screenshot of the immediate feedback on test questions in the ethics e-module.
Once the ethics e-module is completed, the software can send the student's test results directly to the University of Manitoba on-line learning Management System (UMLearn).

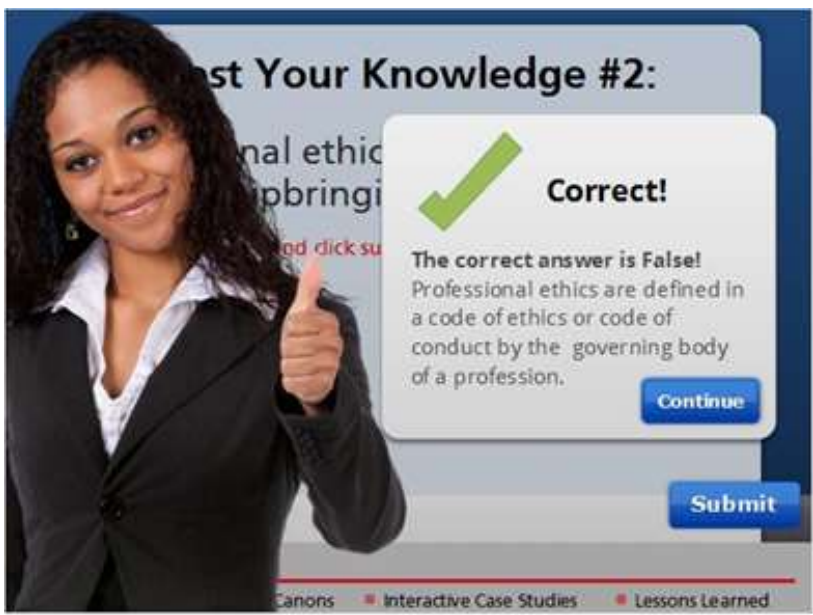

Fig. 6. Immediate feedback on ethics e-module

\subsection{Discussion of Lessons Learned}

Knowing the journey that the students took in arriving at their option (whether it is a choice, action, or thought) is important in the learning process and in assessing the effectiveness of the e-module.

The students will be required to describe the lessons they learned to their professors after completing the emodule and relate them through the critical thinking process.

\subsection{Beta Testing and Feedback}

The accuracy, relevance to the engineering profession, and effectiveness of the ethics e-module is paramount to its success. Therefore preliminary beta-testing of the initial version of the ethics e-module was conducted using selected University of Manitoba students in August 2015 and faculty staff in December 2015. Evaluation sheets were completed along with additional comments for the redesign and revision in the next phase.

Initial feedback was very positive, and included comments such as:

- $\quad$ More context is needed for the e-module. As no instructor is introducing ethics as a prelude to the module, I feel that students will need a lot more context surrounding the idea/understanding of ethics (in engineering) before they begin leaning the specifics and before they begin the activities".

- "Extensive beta testing is important because of the inherent ambiguities of the English language with possible alternative interpretations of the questions". 
- 'Generate each 'instance' of the learning module randomly from a bank of scenarios in order to enhance students learning experience".

Based on the initial feedback, the ethics e-module was updated to address many of the recommendations. A final round of beta-testing and updates, using a larger set of students, professors, and engineers-in-residence, will be completed prior to the ethics e-module implementation in the fall of 2016.

\subsection{Comparison to Other Approaches}

The ethics e-module was compared to the current approach to exposing students to ethics in other engineering programs at the University of Manitoba. The comparison found that engineering ethics is currently taught as a small component of a classroom lecture and in one undergraduate engineering course. One of the disadvantages of the classroom format is that students do not have the time or opportunity to fully explore the ethical decision-making process during class.

The advantage of the e-module approach is that the module can be used as a 'primer' for students to explore the case studies and grasp the ethical decision-making process through numerous case studies at their own pace and time, prior to the larger classroom/group discussion.

\section{FUTURE CONSIDERATIONS}

\subsection{Integration}

The method of integration and implementation for the ethics e-module is through the University of Manitoba online learning management system, 'UMLearn'.

By having the e-module easily accessible, professors and instructors may simply upload the module in their course via an online interface on UMLearn. This would allow professors/instructors to directly manage the system, and have access to students' progress and tests with the emodule.

\subsection{Updates \& Maintenance}

It is desirable for future editors and administrators to update the existing e-module to continually improve the contents. Vendors, or administrators of UMLearn, may also introduce updates to their platforms that may cause instabilities in the e-module that must be addressed.

Therefore, a transition document will be produced to help guide future authors to update and manage the online content of the ethics e-module, as well as create new e-modules. There will also be documentation on how to properly draft, set up, and implement the innovative branching of the storyline ethical scenarios.

\subsection{Measure of Success}

To continually improve the e-module, evaluations will be needed to measure its success. This e-module would be successful if the students were capable of and competent in analyzing ethical conflicts.

The measures for evaluations and surveys will include the following:

- $\quad$ Evaluations of students by professors before and after using e-module to verify that the student students are aware of the Code of Ethics and competent in applying their ethical knowledge.

- Evaluations of the e-module by the professors and teaching assistances on whether or not the e-module was effective in improving student learning.

\section{CONCLUSION}

A self-directed learning ethics e-module for the practice of professional engineering in Manitoba was discussed and presented.

The module highlights the importance of ethics, casestudies with 'branching' options for a variety of real-world scenarios of ethical or unethical choices, and tests with automatic feedback that track a students' progress.

Once implemented, the e-module is expected to form the foundation for future e-modules in various engineering courses at the University of Manitoba.

Ultimately, this ethics e-module will provide graduating engineering students with the tools to make ethical decisions that uphold the fundamental canons of safeguarding the public and the environment, and upholding the integrity of the profession.

\section{Acknowledgements}

The authors gratefully thank the Center for Engineering Professional Practice and Engineering Education, Faculty of Engineering, University of Manitoba, for funding this project.

\section{References}

[1] Articulate Storyline2 Software, www.articulate.com, 2015

[2] Association of Professional Engineers and Geoscientists of Manitoba (APEGM), www.apegm.ca, 2015

[3] Chung, C. A., and Alfred, M., "Design, Development, and Evaluation of an Interactive Simulator for Engineering Ethics Education (SEEE)", Science and Engineering Ethics, 15(2), 189-99, 2009

[4] Clark Aldrich Design, "Ten More Simple But Effective Branching Story Techniques”, www.clarkchart.com, 2014 
Proc. 2016 Canadian Engineering Education Association (CEEA16) Conf.

[5] eLearning Brothers Templates, www.elearningbrothers.com, 2015

[6] Flather, C., "Engineering Ethics", Minerava/MITACS

Engineering Modules Project, University of Manitoba, 2014

[7] Roncin, A., "Thoughts on Engineering Ethics Education in Canada", Canadian Engineering Education Association Conference, Montreal, QC, 2013

CEEA16; Paper 019

Dalhousie University; June 19 - 22, 2016

-6 of $6-$ 